\title{
MODEL TARIKAN PERGERAKAN ORANG DENGAN ANALISA REGRESI DI KAMPUS UNIVERSITAS SEMARANG
}

\author{
Dhamang Budi Cahyono ${ }^{1}$, Agus Muldiyanto $^{2^{*}}$, Anik Kustirini ${ }^{3}$ \\ 1,2,3 Jurusan Teknik Sipil Universitas Semarang \\ e-mail : mulsuga@yahoo.co.id
}

\begin{abstract}
The development of the number of students from year to year is increasing so that the interaction relationship between students, lecturers, employees and managers at Semarang University also increases, this can lead to potential traffic jams and additional facilities for vehicle parking spaces. This study aims to determine the magnitude of the estimated prediction of the movement of people towards Semarang University. The method used in making the model is regression analysis, with the independent variable being the Semarang City GRDP and the fixed variable is the number of active students in the morning and evening classes. The results of the regression equation for the campus draw obtained were for odd semester morning classes were $Y 1=1308.803+0.032 X$, and the equations for the even semesters morning class were Y2 $=1568,960+0.032 \times 4$. The prediction of the attractiveness of class students to Semarang University in 2023 for odd semester is 8,635 people and for even semester is 7173 people, while for odd semester afternoon classes is 9,756 people and for even semester afternoon class is 8,342 people. Predictions in 2023, the largest student motorcycle users occur in the odd semester afternoon class at 8,369 . While the prediction in 2023, the largest student use of the car occurred in the odd semester afternoon class, which amounted to 673.
\end{abstract}

Keywords: attraction; prediction; regression; zone.

\begin{abstract}
ABSTRAK
Perkembangan jumlah mahasiswa dari tahun ke tahun semakin meningkat sehingga hubungan interaksi yang terjadi antara mahasiswa, dosen, karyawan dan pengelola di Kampus Universitas Semarang (USM) juga meningkat, hal ini dapat menimbulkan potensi kemacetan lalu lintas maupun penambahan fasilitas kebutuhan ruang parkir kendaraan. Penelitian ini bertujuan untuk mengetahui besarnya estimasi prediksi tarikan pergerakan orang menuju Kampus USM. Metode yang digunakan dalam membuat model adalah dengan analisis regresi, dengan variabel bebas adalah PDRB Kota Semarang dan variabel tetapnya adalah jumlah mahasiswa aktif kelas pagi dan sore. Hasil persamaan regresi tarikan ke kampus yang didapat adalah untuk semester gasal kelas pagi adalah $Y_{1}=1308,803+0,032$ $X$, dan persamaan untuk semester genap kelas pagi adalah $Y_{2}=1568,960+0,032$ X4. Prediksi tarikan mahasiswa kelas ke Kampus USM pada tahun 2023 untuk semester gasal sebesar 8.635 orang dan untuk semester genapnya sebesar 7173 orang, sedangkan untuk kelas sore semester gasal adalah sebesar 9.756 orang dan untuk semester genap kelas sore sebesar 8.342 orang. Prediksi pada tahun 2023, mahasiswa pengguna sepeda motor terbesar terjadi pada semester gasal kelas sore sebesar 8.369 buah. Sedangkan prediksi pada tahun 2023, mahasiswa penggun mobil terbesar terjadi pada semester gasal kelas sore yaitu sebesar 673 buah.
\end{abstract}

Kata Kunci : prediksi; regresi; tarikan; zona.

\section{PENDAHULUAN}

Kota Semarang mempunyai beberapa wilayah pusat pendidikan tinggi, diantaranya di Tembalang, Gunung Pati, Kaligawe, Sampangan dan Tlogosari yang masing-masing mempunyai corak dan ciri tersendiri. Setiap suatu kegiatan pergerakan mempunyai zona asal dan tujuan, dimana zona asal merupakan zona 
yang menghasilkan perilaku pergerakan, sedangkan zona tujuan adalah zona yang menarik pelaku melakukan kegiatan (John, et.al, 2016).

Pusat kegiatan pendidikan merupakan salah satu tata guna lahan yang mempunyai intensitas yang tinggi dalam menarik pergerakan. Salah satu yang terletak di wilayah Tlogosari adalah Kampus Universitas Semarang (USM). Menurut Purwadi, et.al, ( 2014), gedung perkantoran merupakan salah satu tata guna lahan yang dapat menimbulkan tarikan pergerakan yang besar. Pusat kegiatan pendidikan merupakan tata guna lahan yang mempunyai intensitas yang tinggi untuk menarik pergerakan, timbulnya interaksi bagi arus pergerakan orang baik untuk tujuan pendidikan untuk para mahasiswa dan bekerja untuk dosen dan karyawan (Rezita, et.al, 2014)

Kampus USM merupakan salah satu pusat pendidikan untuk para mahasiswa untuk kuliah, dosen dan karyawan untuk bekerja dan termasuk didalamnya pengelola kantin di dalamnya. Hal ini akan mempengaruhi besarnya tarikan yang terjadi di Kampus USM, pada saat ni mempunyai 6 Fakultas yang meliputi program D3, S1 dan S2 dengan mahasiswa yang relatip banyak jumlahnya, karena adanya mahasiswa reguler pagi dan reguler sore, hal ini juga mempengaruhi proses pembelajarannya.

Pada umum pola perjalanan pelajar dipengaruhi oleh tata guna lahan, semakin banyak jumlah sekolah di suatu wilayah maka akan semakin banyak jumlah pelajar yang menuju wilayah tersebut (Mahmudah, 2016). Interaksi yang terjadi antara mahasiswa, dosen, karyawan dan pengelola kantin semakin meningkat pula, interaksi tersebut dapat menghasilkan pergerakan orang yang cukup besar pula terjadi di USM, hal ini dapat menimbulkan potensi kemacetan arus lalu lintas terutama pada saat jam masuk maupun pulang, apalagi dalam sehari kampus melakukan dua kegiatan yang berurutan yaitu untuk reguler pagi dan reguler sore, kemacetan ini bisa terjadi di luar kampus maupun di dalam kampus USM. Untuk mengatasi kemacetan tersebut diatas maka perlu adanya penyediaan prasarana fasilitas parkir serta pengendalian arus lalu lintas meliputi sirkulasi keluar masuk di area Kampus USM.

Dengan mengetahui besarnya estimasi prediksi pergerakan orang menuju Kampus USM dalam kurun waktu 5 tahun maupun 10 tahun yang akan datang, baik aktivitas pagi dan sore, maka diharapkan permasalahan kemacetan dan kebutuhan ruang parkir dapat diantisipasi dan diatasi.

\section{METODOLOGI}

Tahap pengumpulan data meliputi data primer maupun data sekunder. Data sekunder didapatkan dengan mengajukan permohonan ke pengelola kampus terutama tentang luasan lahan yang di miliki, lahan parkir baik untuk roda dua maupun roda empat, luas kantin, sedangkan data primer dengan melakukan wawancara/kuesioner terhadap mahasiswa D3,S1, S2, dosen, karyawan dan pengelola kantin, kopima dan pengamatan kondisi di kampus USM baik pagi, sore dan malam.

Jumlah Sampel pada tingkat ketelitian/kepercayaan atau kesalahan yang dikendaki, hal ini sangat tergantung pada sumber dana, waktu dan tenaga yang tersedia. Menurut Sugiyono, (2009), rumus untuk menghitung sampel dalam populasi pada penelitian ini sebagai berikut:

$$
S=\frac{Y^{2} \cdot N \cdot P \cdot Q}{d^{2}(n-1)+Y^{2} \cdot P \cdot Q}
$$

Keterangan :

$\mathrm{S}=$ Jumlah sampel

$\mathrm{P}=$ Jumlah populasi

$\mathrm{Y}^{2}$ dengan $\mathrm{dk}=1$, taraf kesalahan bisa $1 \%, 5 \%, 10 \%$ 
$P=Q=0,5$

$\mathrm{d}=0,05$

Variabel tetap disini adalah jumlah pergerakan orang ke kampus USM, sedang variabel bebas adalah meliputi ; jumlah mahasiswa (D3,S1,S2), dosen, karyawan dan karyawan kantin dan kopima. Sedangkan variabel bebasnya adalah PDRB kota Semarang.

\section{HASIL DAN PEMBAHASAN}

Model tarikan pergerakan orang akibat keberadaan Kampus USM, digunakan untuk memprediksi besarnya tarikan pergerakan orang menuju kampus USM yang digunakan dapat menggunakan peramalan model ekonometrik, variable bebas (independent variable) adalah PDRB kota Semarang. Analisisnya menggunakan analisis regresi linier berganda dengan menggunakan software Statistic Program for Special Science (SPSS) 23.

\section{Analisis Regresi \\ Kelas pagi semester gasal}

Perhitungan Persamaan Regresi untuk mahasiswa kelas pagi semester gasal, adalah :

$\mathrm{R}=0,959, \mathrm{R}^{2}=0,848, \mathrm{~F}$ hitung $=23,016$ dan $\mathrm{t}$ hitung $=4,797$ dan persamaan regresinya adalah : $Y_{1}=1308,803+0,032 X, Y_{1}$ adalah besarnya tarikan mahasiswa, sedangkan X3 adalah PDRB Kota Semarang. Nilai koefisien determinasi $\left(R^{2}\right)=0,959$, yang berarti bahwa 95,9 \% variasi jumlah mahasiswa semester gasal kelas pagi dapat diwakili dengan persamaam tersebut diatas. Dengan derajat kebebasan 4 , nilai $F=23,016>$ dari $F$ tabel $(6,39)$, yang dapat diartikan bahwa $95 \%$ variasi yang terjadi pada jumlah mahasiswa kelas pagi semester gasal dapat dijelaskan oleh nilai PDRB. Nilai $\mathrm{t}$ hitung $=4,797>$ nilai $\mathrm{t}$ tabel $(2,132)$, yang berarti nilai Koef $X 3$ berati bagi persamaan tersebut diatas. Persamaan ini mengandung arti bahwa jumlah mahasiswa kelas pagi semester gasal sangat ditentukan oleh nilai PDRB, yaitu tingkat kesejahteraan penduduk kota Semarang.

\section{Kelas pagi semester genap}

Perhitungan Regresi untuk mahasiswa kelas pagi semester genap, adalah sebagai berikut :

$R=0,921, R^{2}=0,848, F$ hitung $=11,127$ dan $t$ hitung $=3,336$ dan persamaan regresinya adalah : $Y_{2}=1568,960+0,032 X, Y_{2}$ adalah besarnya tarikan mahasiswa, sedangkan $X$ adalah PDRB Kota Semarang. Nilai koefisien determinasi $\left(R^{2}\right)=0,921$, yang berarti bahwa $92,1 \%$ variasi jumlah mahasiswa semester gasal kelas pagi dapat diwakili dengan persamaam tersebut diatas. Dengan derajat kebebasan 4 , nilai $F=11,127>$ dari $F$ tabel $(6,39)$, yang dapat diartikan bahwa $95 \%$ variasi yang terjadi pada jumlah mahasiswa kelas pagi semester gasal dapat dijelaskan oleh nilai PDRB. Nilai $t$ hitung $=3,336>$ nilai $t$ tabel $(2,132)$, yang berarti nilai Koef $X 3$ berati bagi persamaan tersebut diatas. Persamaan ini mengandung arti bahwa jumlah mahasiswa kelas pagi semester gasal sangat ditentukan oleh nilai PDRB, yaitu tingkat kesejahteraan penduduk kota Semarang.

\section{Kelas sore semester gasal}


Perhitungan Regresi untuk mahasiswa kelas sore semester gasal, adalah sebagai berikut :

$\mathrm{R}=0,867, \mathrm{R}^{2}=0,752, \mathrm{~F}$ hitung $=6,056$ dan $\mathrm{t}$ hitung $=2,461$ dan persamaan regresinya adalah : $\mathrm{Y}_{3}=6226,152+0,023 \mathrm{X}, \mathrm{Y}$ adalah besarnya tarikan sedangkan X1 adalah PDRB Kota Semarang. Dengan derajat kebebasan 4, nilai $F=6,056<$ dari $F$ tabel $(6,39)$, yang dapat diartikan bahwa variasi yang terjadi pada jumlah mahasiswa kelas sore semester gasal tidak dapat dijelaskan oleh nilai PDRB. Nilai t hitung $=2,461>$ nilai t tabel $(2,132)$ dan nilai $F=6,056<$ dari $F$ tabel $(6,39)$, yang berarti nilai diatas, persamaan ini mengandung arti bahwa jumlah mahasiswa kelas sore semester gasal tidak ditentukan oleh nilai PDRB.

\section{Kelas sore semester genap}

Perhitungan Regresi untuk mahasiswa kelas sore semester gasal, adalah sebagai berikut :

$\mathrm{R}=0,194, \mathrm{R}^{2}=0,038, \mathrm{~F}$ hitung $=0,079$ dan $\mathrm{t}$ hitung $=0,28$ dan persamaan regresinya adalah : $\mathrm{Y}_{4}=6226,152+0,023 \mathrm{X}, \mathrm{Y}$ adalah besarnya tarikan sedangkan X1 adalah PDRB Kota Semarang. Dengan derajat kebebasan 4, nilai $F=6,056<$ dari $F$ tabel $(6,39)$, yang dapat diartikan bahwa $95 \%$ variasi yang terjadi pada jumlah mahasiswa kelas sore semester gasal tidak dapat dijelaskan oleh nilai PDRB. Nilai $t$ hitung $=2,461>$ nilai $t$ tabel $(2,132)$ dan nilai $F=6,056<$ dari $F$ tabel $(6,39)$, yang berarti nilai diatas, persamaan ini mengandung arti bahwa jumlah mahasiswa kelas sore semester gasal tidak ditentukan oleh nilai PDRB.

\section{Pembahasan}

\section{Prediksi tarikan ke kampus USM mahasiswa aktif kelas pagi}

Prediksi mahasiswa aktif kelas pagi baik semester gasal dan genap dapat di prediksikan tarikan nya adalah seperti yang tercantum dalam Gambar 1 di bawah ini.

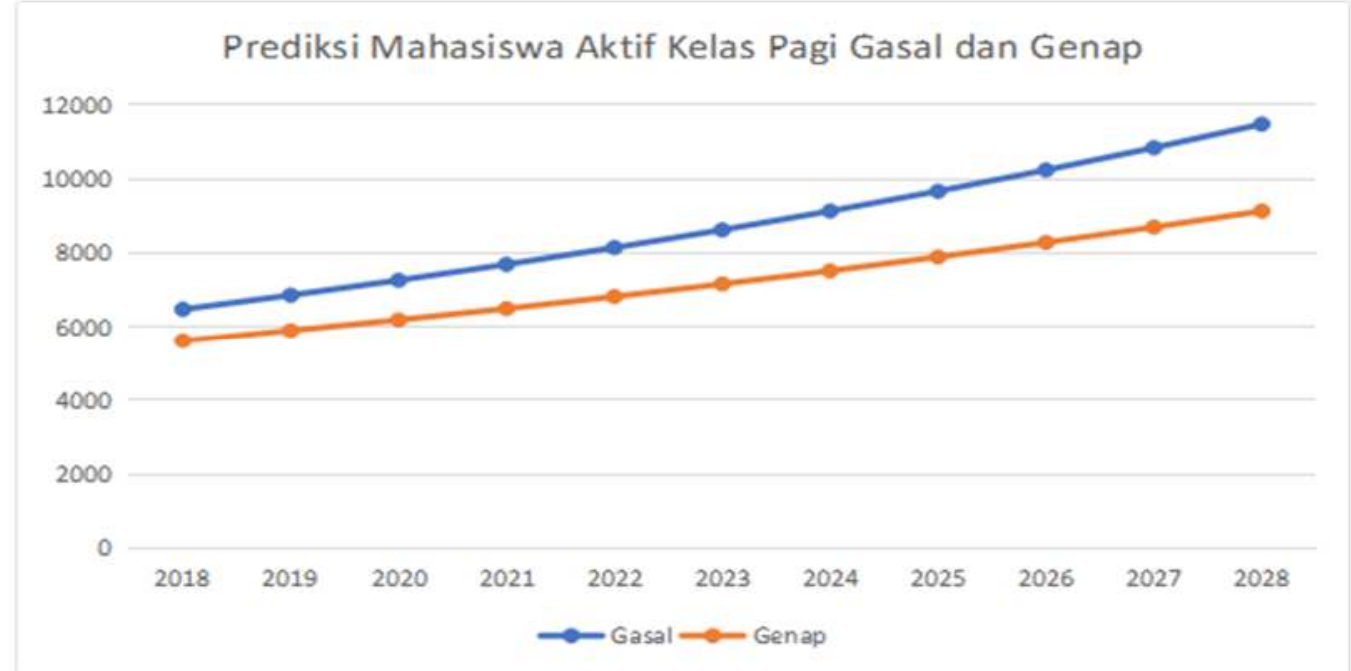

Gambar 1. Grafik Prediksi Tarikan Mahasiswa Aktif Kelas Pagi

Sumber : Penelitian,2019

Dari Gambar 1 dapat dijelaskan sebagai berikut, bahwa prediksi pertumbuhan 5 tahun pertama pada tahun 2023 adalah sebanyak 8635 orang pada semester gasal dan 7173 orang pada semester genap. Pada 5 tahun berikutnya pada 2028 adalah sebanyak 11490 orang pada semester gasal dan 9141 orang pada semester genap. 


\section{Prediksi tarikan ke kampus USM mahasiswa aktif kelas sore}

Prediksi mahasiswa aktif kelas sore baik semester gasal dan genap dapat di prediksikan tarikan nya adalah seperti yang tercantum dalam Gambar 2 di bawah ini.

\section{Prediksi Mahasiswa Aktif Kelas Sore Gasal dan Genap}

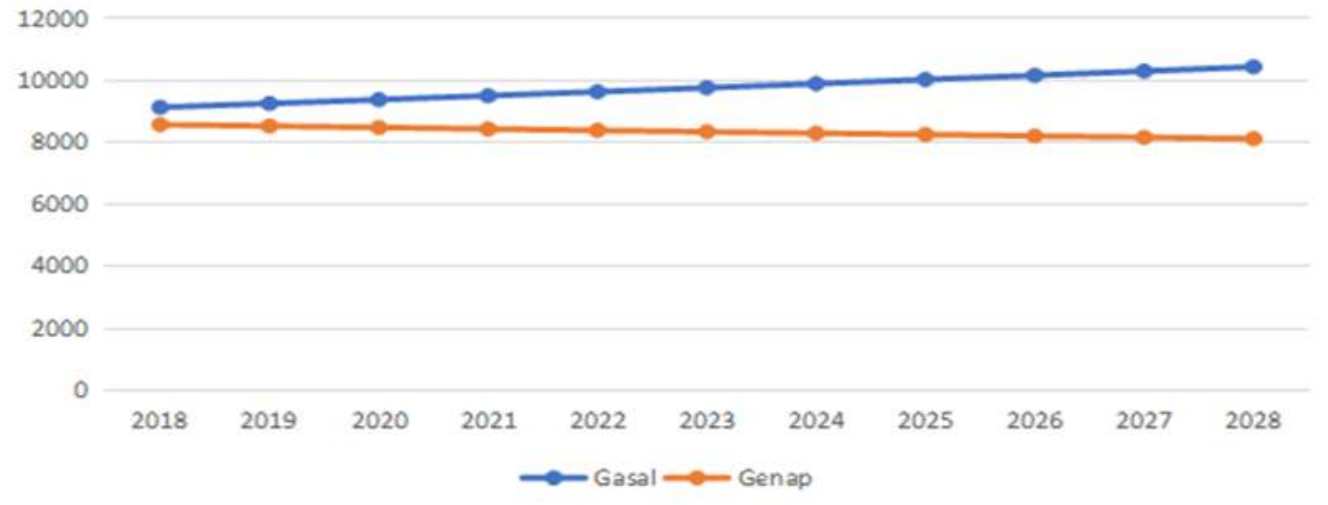

Gambar 2. Grafik Prediksi Mahasiswa Aktif Kelas Sore

Sumber : Penelitian, 2019

Dari Gambar 2 dapat dijelaskan sebagai berikut, bahwa prediksi pertumbuhan 5 tahun pertama pada tahun 2023 adalah sebanyak 9756 orang pada semester gasal dan 8342 orang pada semester genap. Pada 5 tahun berikutnya pada 2028 adalah sebanyak 10428 orang pada semester gasal dan 8119 orang pada semester genap.

\section{Prediksi mahasiswa pengguna motor kelas pagi dan sore}

Untuk prediksi 5 tahun dan sepuluh tahun yang akan datang yaitu pada tahun 2023 dan pada tahun 2028, mahasiswa aktif kelas pagi dan sore dapat dilihat pada Gambar 3 di bawah ini.

\section{Motor Pagi dan Sore}

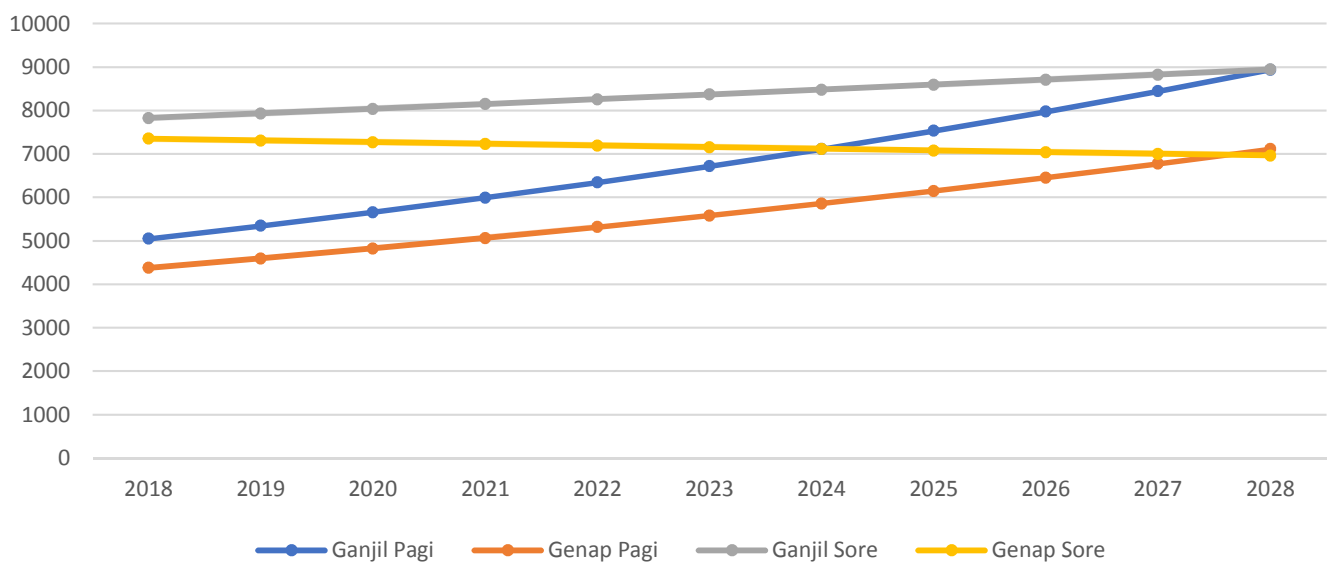


Dari Gambar 3 dapat dijelaskan sebagai berikut, bahwa prediksi pertumbuhan jumlah motor 5 tahun pertama pada tahun 2023 adalah sebanyak 6720 buah pada semester gasal dan 4380 buah pada semester genap untuk kelas pagi . Sedangkan 8369 buah pada semester gasal dan 7156 buah pada semester genap untuk kelas sore. Pada 5 tahun berikutnya pada 2028 adalah sebanyak 8943 buah pada semester gasal dan 7115 buah pada semester genap untuk kelas pagi dan 8945 untuk semester gasal dan 6965 buah pada semester genap untuk kelas sore.

\section{Prediksi mahasiswa pengguna mobil dan sepeda kelas pagi}

Untuk prediksi mahasiswa kelas pagi baik semester gasal dan genap untuk, 5 tahun dan sepuluh tahun yang akan datang yaitu pada tahun 2023 dan pada tahun 2028, mahasiswa aktip kelas pagi dan sore dapat dilihat pada Gambar 4 di bawah ini.

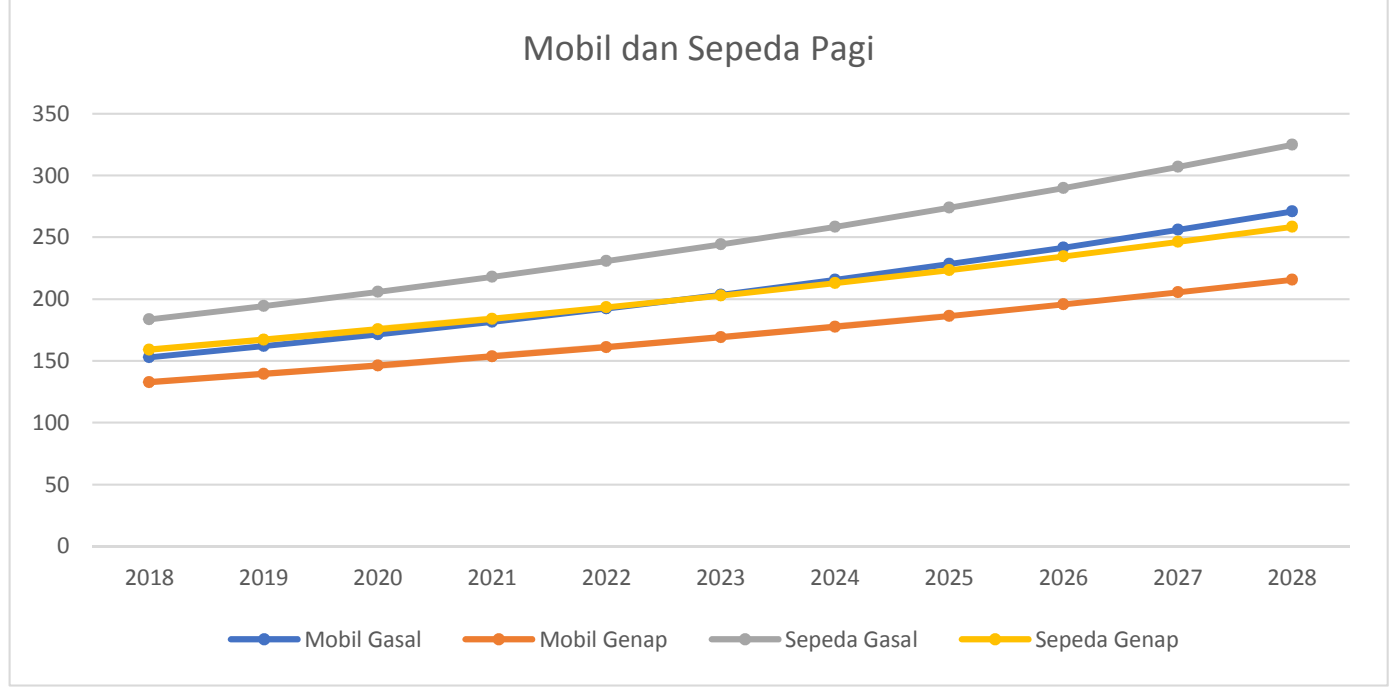

Dari Gambar 4 dapat dijelaskan sebagai berikut, bahwa prediksi pertumbuhan jumlah mobil dan sepeda 5 tahun pertama pada tahun 2023 adalah sebanyak 204 buah mobil pada semester gasal dan 169 buah mobil pada semester genap untuk kelas pagi dan 244 buah sepeda pada semester gasal dan 203 buah sepeda pada semester genap. Pada 10 tahun yang akan datag yaitu tahun 2028 adalah sebanyak 271 buah mobil pada semester gasal dan 216 buah mobil pada semester genap untuk kelas pagi dan 325 buah sepeda pada semester gasal dan 259 buah sepeda pada semester genap.

\section{Prediksi mahasiswa pengguna mobil dan sepeda kelas sore}

Untuk prediksi mahasiswa kelas pagi baik semester gasal dan genap untuk, 5 tahun dan sepuluh tahun yang akan datang yaitu pada tahun 2023 dan pada tahun 2028, mahasiswa aktip kelas pagi dan sore dapat dilihat pada Gambar 5 di bawah ini. 


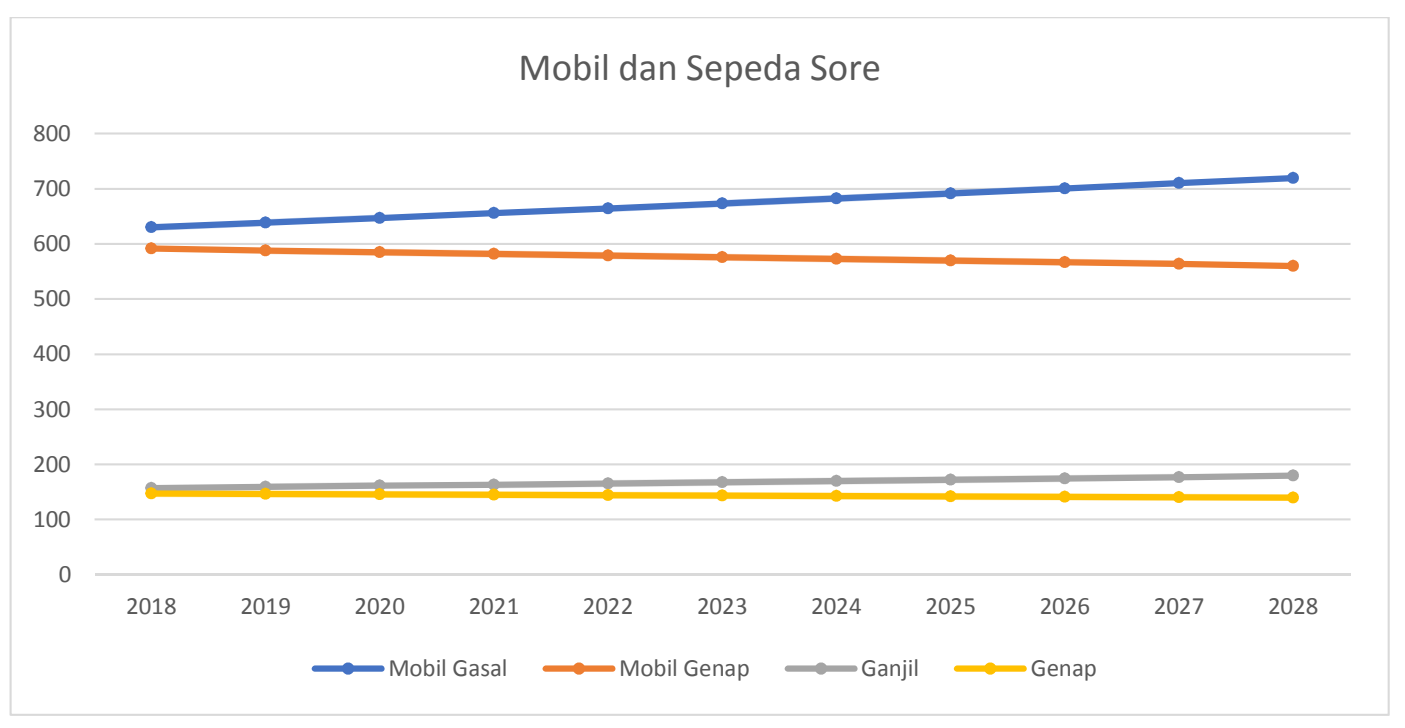

Gambar 5. Grafik Prediksi Jumlah Mobil dan sepeda untuk Kelas Sore

Sumber : Penelitian, 2019

Dari Gambar 5 dapat dijelaskan sebagai berikut, bahwa prediksi pertumbuhan jumlah mobil dan sepeda 5 tahun pertama pada tahun 2023 adalah sebanyak 673 buah mobil pada semester gasal dan 576 buah mobil pada semester genap untuk kelas sore dan 168 buah sepeda pada semester gasal dan 143 buah sepeda pada semester genap. Pada 10 tahun yang akan datang yaitu pada tahun 2028 adalah sebanyak 720 buah mobil pada semester gasal dan 560 buah mobil pada semester genap untuk kelas sore dan 179 buah sepeda pada semester gasal dan 140 buah sepeda pada semester genap.

\section{KESIMPULAN}

Dari hasil analisis yang telah dilakukan, maka dapat disimpulkan bahwa model tarikan pergerakan orang dengan nilai regresi di Kampus Universitas Semarang untuk kelas pagi semester gasal adalah $Y=1308,803+0,032 \times 3$ dan semester genap adalah $Y=1568,960+0,032 X 4, X_{3}$ dan $X_{4}$ PDRB kota semarang, sedangkan $Y$ adalah tarikan yang terjadi pada saat semester gasal dan genap kelas pagi, sedangkan untuk klas sore persamaan dengan regresi dengan PDRB sebagai variabel bebas tidak ada yang sesuai. Prediksi pertumbuhan tarikan mahasiswa aktif kelas pagi ke kampus USM, pada tahun 2023 adalah sebanyak 8635 orang pada semester gasal dan 7173 orang pada semester genap. Pada tahun 2028 adalah sebanyak 11490 orang pada semester gasal dan 9141 orang pada semester genap. Prediksi pertumbuhan tarikan mahasiswa aktif kelas sore ke kampus USM, pada tahun 2023 adalah sebanyak 9756 orang pada semester gasal dan 8342 orang pada semester genap. Pada tahun 2028 adalah sebanyak 10428 orang pada semester gasal dan 8119 orang pada semester genap. Prediksi pertumbuhan mahasiswa menggunakan motor pada tahun 2023 adalah sebanyak 6720 buah pada semester gasal dan 4380 buah pada semester genap untuk kelas pagi dan 8369 buah pada semester gasal dan 7156 buah pada semester genap untuk kelas sore. Pada tahun 2028 adalah sebanyak 8943 buah pada semester gasal dan 7115 buah pada semester genap untuk kelas pagi dan 8945 untuk semester gasal dan 6965 buah pada semester genap untuk kelas sore. Prediksi pertumbuhan jumlah mahasiswa kelas pagi pengguna mobil dan sepeda pada tahun 2023 adalah sebanyak 204 buah mobil pada semester gasal dan 169 buah mobil pada semester genap untuk kelas pagi dan 244 buah sepeda pada semester gasal dan 203 buah sepeda pada semester genap. Pada 10 tahun yang akan 
datang yaitu tahun 2028 adalah sebanyak 271 buah mobil pada semester gasal dan 216 buah mobil pada semester genap untuk kelas pagi dan 325 buah sepeda pada semester gasal dan 259 buah sepeda pada semester genap.

\section{DAFTAR PUSTAKA}

John, H. F., et.al. 2016, Model Tarikan PergerakanTransportasi Pada Kompleks LIPPO Plaza, Flobamora Mall Dan Hypermart Bundaran PU Kota Kupang,Jurnal Teknik Sipil, Volume V, No. 2, September 2016.

Mahmudah, N. 2016, Pemodelan Bangkitan Perjalanan Pelajar di Kabupaten Sleman, Jurnal Teknik Sipil, Volume 13, No.4, 4 April 2016; 301-307.

Purwadi, E.S., et.al. 2014, Kajian Pemodelan Tarikan Pergerakan Ke Gedung Perkantoran (Studi Kasus Kota Surakarta), e-Jurnal Matriks Teknik Sipil, Volume 2, No.1, Maret 2014

Sugiyono. 2009, Metode Penelitian Kuantitatif Kualitatif Dan R\&D, Cetakan ke 6,CV. Alfabeta, Bandung.

Rezita, D.A.,et.al. 2014, Studi Pembuatan Model Tarikan Pergerakan Orang Pada Pusat Kegiatan Pendidikan Dengan Metode Analisis Regresi, (Studi Kasus : Kampus Universitas Brawijaya), Volume 1, No.1, http://sipil. studentjournal.ub.ac.id.

Tamin, Z.O. 2000, Perencanaan dan Permodelan Transportasi. Edisi Kedua. Bandung, ITB. 